\section{SOME CAUSES OF DISAPPOINTMENT FOLLOWING REMOVAL OF TONSILS AND ADENOIDS.}

BY WILIIAM WILSON, M.D., B.Sc. MANCH., ASSISTAN'T SURGEON, ST. JOHN'S EAR HOSPITAL, MANCHESTER.

THE routine tonsil and adenoid operation, like all routine methods, shows a considerable percentage of failures, more especially in regard to hearing capacity. Recently I have entirely relinquished the rapid operation under ethyl chloride, and have substituted a more painstaking method under chloroform and ether, specially adapting it to the conditions present in the nasopharynx. The reason for this is that whilst results were good with regard to efficient nasal respiration the ventilation of the tympanic cavity was not so frequently satisfactory; hence some amount of deafness persisted. To understand the reasons for these failures, it is necessary to review briefly the surgical relations of the Eustachian orifices.

The ostium pharyngeum is situated rather less than half an inch behind the posterior end of the inferior turbinal. (Fig. 1.) The cartilage is shaped



Diagram showing the relations of Eustachian orifice to Rosenmiiller's fossa, and to the muscles acting upon the aperture. LC, Levator cushion (levator palati muscle). s, Salpingo-palatal fold. T, Origin of tensor pal,ti muscle. PT, Pharyngeal tonsil. FR, Fossa of Rosenmüller. EC, Eustachian cushion. SF, Salpingo-pharyngeal muscle.

like a question mark (?), showing a short anterior horn and a larger posterior cartilaginous horn; the anterior horn is prolonged as a mass of somewhat soft fibrous tissue. When the Eustachian orifice opens, as in swallowing, the two pillars separate and the lower border is pushed up : the ostium thus assumes a triangular form. The muscles acting upon the orifice are three in number-the dilator tubø (a portion of the tensor palati), the levator palati, and the salpingo-pharyngeus. The first takes origin from the anterior cartilaginous horn and from the areolar tissue below it; it stretches over the hamular process and is inserted into the soft palate ; its action is to pull forward the anterior fibrous wall. The levator palati forms a projection just below the ostium, and when contracted bulges into the lumen; it also is inserted into the soft palate; its action is to push up the floor and push back the posterior cartilage. The salpingopharyngeus is a tiny muscle which causes the salpingo-pharyngeal fold; it pulls down and back the posterior cartilaginous horn.

Politzer has demonstrated that the healthy membrana tympani bulges in and out with a rhythmic motion, whilst every act of swallowing causes the tube to open and the membrana to fall in, so that during the act hearing is dulled. By these means the tympanic cavity is constantly being ventilated.

From the above it will be readily understood that anything preventing this opening of the pharyngeal orifice-whether paralyses of soft palate or pharynx or direct mechanical obstruction to the cartilage from tumours or lymphatic tissue, will cause stagnation of air in the middle ear. Soon the membrana tympani will fall inwards and later will become adherent to the inner wall of the tympanic cavity.

Now, if the nasopharynx be carefully examined (under the anæsthetic a thorough digital exploration should be made) there will be detected behind the Eustachian orifice a vertical channel which opens into a wider chamber; in children suffering from deafness this chamber is usually more or less full of lymphatic tissue pressing anteriorly upon the posterior aspect of the Eustachian cartilage. It will be found also that the main adenoid mass (the enlarged pharyngeal tonsil) does not encroach upon the tube; the soft palate is in a state of laxity and will readily allow this examination. (Fig. 2.) This

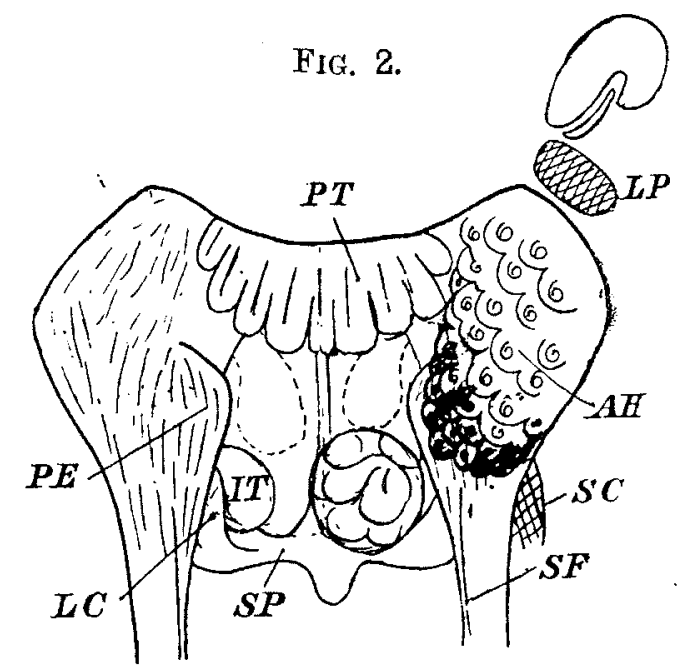

Diagram showing posterior ends of inferior turbinals stretching soft-palate muscles and thus preventing adequate opening of Eustachian orifice; also adenoid tissue of opening of Eustachian orifice; also adenoid tissue of Rosenmuller's fossa preventing opening of Eustachian orifice backwards. Lc, Levator cushion. PE, Posterior cornu, Eustachian orifice. PT, Pharyngeal tonsil. $\mathbf{I}_{\mathbf{S}} \mathrm{P}$ Levator palati muscle. $\Delta \mathrm{E}$, Adenoid hypertrophy in fossa of Rosenmuller. sc, Superior constrictor muscle. SF. Salpingo-pharyngeal fold. SP, Soft palate. IT, Inferior turbinate.

laxity of the palatal muscles affords a good sign of the presence of adenoids; if the patient repeats the sound "Ah" the soft palate, examined through the anterior nares, will not be observed to rise upwards. After removal of this main adenoid mass, with the return of nasal respiration we can observe a return of tonus in the soft palate; yet the membrana tympani remains retracted. This is due to the inability of the tensor palati, levator palati, and salpingo-pharyngeus to open the tubal ostium on account of the mechanical obstruction from the growth extending from Rosenmüller's fossa. The ear can be ventilated with difficulty by forcible politzerisation, but more easily by catheterisation which mechanically forces air through the ostium. Is it not better to remove carefully all remains of adenoid tissue from around the Eustachian orifice, to treat it locally with astringents (e.g., silver" nitrate 10 per cent.), and allow the patient to ventilate his own ear in the natural way? The smallest ring-knife or Mackie's curette will be found best for this purpose, and should be guided by the finger of the other hand. 
Many failures result from neglect to remove the enlarged posterior end of the inferior turbinals, which are far more obstructive to respiration than are the faucial tonsils; of course, in many cases they would diminish in size after removal of the pharyngeal tonsil, but as this would occupy from two to three years, during which time the nasal obstruction would continue, why operate at all? A patient who undergoes an operation for nasopharyngeal obstruction deserves a perfectly functional result. It is no use scraping the pharynx as a routine when the entire obstruction is due to nasal stenosis.

The posterior ends may be removed by snipping them away with one of the guillotines invented by Lake, but often it is impossible to get these instruments easily down both sides of the nostril. In this case a strong nasal snare may be employed; the loop should be guided over the posterior ends with a finger in the nasopharynx.

Of special interest, also, is the persistence of symptoms of "throat cough" and laryngeal catarrh after operation. In many cases this will be found to be due to either a septic condition or actual hypertrophy of the lingual tonsil, which may be in contact with the epiglottis. It is very possible that after complete extirpation of the faucial and pharyngeal tonsils the remaining lingual tonsil undergoes some compensatory hypertrophy.

If there is found such a degree of cartilaginous septal deviation that one nostril is completely blocked, it is essential to obtain a free airway or sooner or later an acute catarrh supervening will cause either collapse of the membrana tympani or middle-ear suppuration on that side. The best operation is some form of Watson-Gleason operation which can be performed with a scalpel and a pair of Killian's septal compression forceps.

the deflection is slight it may be rectified by a dental splint in many cases.

After-treatment is quite as important as the operation itself. It consists of (1) breathing exercises daily; (2) politzerisation weekly for six weeks, then omitted for one week, and repeated for six weeks if required; and (3) dental appliances necessary perhaps to restore a narrow palatal arch and septal deviation which is not severe enough to require operative treatment.

Manchester.

\section{A NOTE ON PERFORATION OF GASTRIC ULCERS INTO THE HEART ITSELF,} WITH REPORT AND PHOTOGRAPH OF A CASE.

\section{BY FRANK E TYLECOTE, M.D. VICT., D.P.H.,} M.R.C.P. LoND.,

SENIOR PHYSICIAN TO THE SALFORD ROYAL HOSPITAL; VISITING PHYSICIAN TO THE SOU'TH MANCHESTER UNION HOSPITALS.

THIs condition is one of extreme rarity. After a prolonged search $I$ have been able to find only four cases recorded in the literature, and in only one of these was the diagnosis suggested before death.

The first case to be recorded was that of Oser ${ }^{5}$ in 1880. His clinical record is accompanied by futh details of the post-mortem findings of Hans Chiari. ${ }^{3}$ The patient was a woman, aged 71, who lived three and a half days after the first hæmatemesis. The ulcer was a round one measuring $2 \mathrm{~cm}$. across ; it was situated on the lesser curvature, at the cardiac end of the stomach, $5 \mathrm{~cm}$. from the cardiac orifice.

In the next year Brenner, ${ }^{1}$ also in Vienna, published the second case. In this case both hæmatemesis and melæna occurred before death, which did not take place for fully four days after the onset of the symptoms. The ulcer was again situated on the lesser curvature, $5 \mathrm{~cm}$. from the cardia, but was of the size of the palm of the hand ("fast handtellergross"). At the left base there were old pleural adhesions of rheumatic origin.

The third case, the first to be recorded in English, was that of Finny, ${ }^{4}$ in 1886 . The ulcer was on the anterior wall of the stomach, $2 \frac{1}{2}$ inches from the cardiac orifice and 2 inches from the lesser curvature. The pericardial cavity had been obliterated by old rheumatic pericarditis. The perforation was direct into the left ventricle, about an inch from the apex. It was hidden by a musculus papillaris attached to the postexior surface of the mitral valve. There was a serous exudate in the left pleural cavity. There were adhesions between the pulmonary and diaphragmatic pleura and also between the stomach and the diaphragm. The bronchial glands showed caseation and some calcification. The stomach and the whole length of the intestines were full of fluid blood.

Brunniche ${ }^{2}$ published the fourth case in 1887. His patient was a male, and the ulcer was on the lesser curvature. On the posterior surface of the left ventricle was an ulcer of the size of a shilling The stomach contained a blood clot of the size of the fist. The ulcer was not covered by any membrane, there was no sign of any pus, and the heart itself did not contain any stomach contents.

In 1894 Ludwig Pick ${ }^{6}$ published a monograph on perforation of the diaphragm by gastric ulcer, and of 28 cases collected by him only 10, or 35.7 per cent., involved the pericardium. Of these $10 \mathrm{only}$ the 4 I have referred to, or 143 per cent. of the whole, involved the heart muscle itself. His monograph makes it clear that in these cases a perigastritis is always present, and that it is vi $\hat{a}$ the most anterior portion of that part of the diaphragm on which the heart rests that the entry is gained. Of 10 of Pick's cases in which the ulcer was on the lesser curvature, 6 perforated the pericardium, 3 the left pleura, and 1 the mediastinum. Where the ulcer was ( 5 cases) situated in the fundus, the left pleura was always perforated. Of 3 in the cardiac region, 2 perforated the left pleural sac and the third the pericardium. All ulcers on the posterior wall perforated the left pleura, while the one case on the anterior wall involved the heart muscle. All were chronic ulcers with thickened and indurated edges, and their bases adherent to neighbouring organs, so that they were not able to cicatrise, contract, and heal up. As one would expect-taking into account the relationship of the pylorus to the liver-in spite of the frequency of pyloric ulcer, it was only met with 3 times in Pick's 28 cases of perforation of the diaphragm.

In my own case the subject was a woman aged 70 . She went to bed as usual at 11 o'clock on a Sunday night. At 8 o'clock on the following morning she was found kneeling at the side of the bed, dead and cold. The bed had been slept in. The chamber utensil contained blood. I ascertained that she had not found it necessary to obtain medical advice for nine or ten months previously; the medical man she then consulted has been good enough to inform me that she complained of indefinite pains about the lower part of the chest and in the epigastrium, there being no physical signs of organic disease, either thoracic or abdominal. She was given one or two bottles of medicine by him, and as she did not consult anyone again presumably felt better. 